\title{
Effect of preoperative jaundice on long- term prognosis of gallbladder carcinoma with radical resection
}

Xin-wei Yang ${ }^{1+}$, Jun-yi Chen ${ }^{2+}$, Zhi-jian Wen ${ }^{3+}$, Yu-long Li ${ }^{1+}$, Fei-yu Wang ${ }^{4 \dagger}$, Liang Li ${ }^{1}$, Jue Yang ${ }^{1}$, Ping-hua Yang ${ }^{1}$, Bao-hua Zhang ${ }^{1 *}$ and Feng Shen ${ }^{1 *}$

\begin{abstract}
Purposes: This study was designed to evaluate the effect of preoperative jaundice on long-term prognosis of gallbladder carcinoma (GBC) after radical resection (RO).

Methods: A total of 267 GBC patients who underwent R0 resection from January 2004 to December 2014 were enrolled, including 54 patients with preoperative jaundice and 213 patients without jaundice. The clinicopathological parameters between the two groups were compared, and the correlation between preoperative jaundice and the long-term prognosis was furtherly analyzed.

Results: Unilateral and multivariate analyses of 267 GBC patients showed that the depth of tumor invasion (pT stage), lymphatic metastasis, and hepatic invasion were independent prognostic factors. The univariate and multivariate analysis of 54 GBC patients with preoperative jaundice showed that only PT stage was an independent factor for prognosis. Furthermore, the intraoperative blood transfusion and pT stage were significant different between longterm survival (survive for more than 3 years) and those who died within 3 years $(P<0.05)$.

Conclusion: Preoperative jaundice was not the independent factor resulting in the poor long-term prognosis of gallbladder carcinoma after RO resection. The $\mathrm{pT}$ stage was the only long-term prognostic factor in all GBC patients regardless of preoperative jaundice.
\end{abstract}

Keywords: Jaundice, Gallbladder carcinoma, RO, Long-term prognosis, pT stage

\section{Introduction}

Gallbladder carcinoma (GBC) that has invaded the submucosa without lymph node metastasis may have a favorable prognosis after surgical resection [1]. However, GBC has a tendency to invade the surrounding organs, especially to the hilar and hepatoduodenal ligaments. This usually leads to obstructive jaundice, which usually

\footnotetext{
* Correspondence: weicelia@163.com; shenfengdfgd@yahoo.com.cn ${ }^{+}$Xin-wei Yang, Jun-yi Chen,Zhi-jian Wen, Yu-long Li and Fei-yu Wang contributed equally to this work.

${ }^{1}$ Eastern Hepatobiliary Surgery Hospital, Second Military Medical University, Changhai Road 225, Shanghai 200438, China

Full list of author information is available at the end of the article
}

indicates that the disease is in advanced stage and cannot be surgically resected [2].

Previous reports have suggested that GBC patients with preoperative jaundice were significantly associated with poor prognosis [3-7]. In addition, some recent studies also have found that preoperative jaundice or extrahepatic bile duct invasion were independent predictors of poor prognosis $[8,9]$. Even so, some scholars supported surgical resection in such advanced patients $[10,11]$. Our previous study [12] has found that the jaundiced patients have lower survival rates than the non-jaundiced patients. The multivariate analysis showed that preoperative jaundice was not a significant

(c) The Author(s). 2020 Open Access This article is licensed under a Creative Commons Attribution 4.0 International License, which permits use, sharing, adaptation, distribution and reproduction in any medium or format, as long as you give appropriate credit to the original author(s) and the source, provide a link to the Creative Commons licence, and indicate if changes were made. The images or other third party material in this article are included in the article's Creative Commons licence, unless indicated otherwise in a credit line to the material. If material is not included in the article's Creative Commons licence and your intended use is not permitted by statutory regulation or exceeds the permitted use, you will need to obtain permission directly from the copyright holder. To view a copy of this licence, visit http://creativecommons.org/licenses/by/4.0/ The Creative Commons Public Domain Dedication waiver (http://creativecommons.org/publicdomain/zero/1.0/) applies to the data made available in this article, unless otherwise stated in a credit line to the data. 
risk factor of poor outcome in GBC patients who underwent surgical resection with curative intent (R0 and R1 resections) [12]. However, the role of preoperative jaundice in the prognosis evaluation of GBC patients after R0 resection has never been reported. The aim of this study was to evaluate the long-term prognostic value of preoperative jaundice in $\mathrm{GBC}$ patients after $\mathrm{R} 0$ resection.

\section{Materials and methods}

\section{Patients}

A prospectively maintained hepatobiliary surgery database at the Eastern Hepatobiliary Hospital was reviewed for all patients with a diagnosis of GBC who underwent surgical resection with curative intent between January 2004 and December 2014. Permission from the Second Military Medical University's Institutional Review Board was obtained prior to data review. Written informed consent was obtained from all patients for surgical treatment and pathological examinations according to the institutional guidelines.

Preoperative jaundice was defined as the elevated total bilirubin level $(>3.0 \mathrm{mg} / \mathrm{dl})$. Resection completeness was classified into R0 microscopically margin-negative resection, R1 microscopically positive margin, and R2 macroscopic residuals on surgical margins. R0 was considered to be radical resection. During the operation, 10 patients underwent rapid freezing to confirm the negative margin, which was confirmed by the final pathological results. All patients who had undergone either R1 or R2 surgery were excluded from the analysis. All surgeries were performed by a single treatment team. Stage grouping was performed according to the pTNM classification system of UICC, 8th edition [13].

\section{Surgical procedures}

All patients were given preoperative imaging to assess the accurate range of tumor invasion, before they were scheduled for surgery. In order to reduce the risk of postoperative liver failure, preoperative portal vein embolization (PVE) was performed in patients with more than $60 \%$ of hepatic parenchymal resection [6]. Hepatectomy was scheduled 2-3 weeks after PVE when liver hypertrophy had been confirmed by volumetry, and the serum bilirubin level was lower than $6 \mathrm{mg} / \mathrm{dl}$. Two patients underwent hemihepatic PVE prior to extended right hemihepatectomy.

All patients underwent en bloc dissection of regional lymph nodes (lymph nodes along the hepatoduodenal ligament and common hepatic artery and behind the pancreatic head). Hepatectomies were carried out in all 276 patients. When the adjacent organ was found to be invaded, en bloc resection was performed simultaneously, such as pancreaticoduodenectomy, partial gastrectomy, partial duodenal resection, and colon resection. Vascular resection (hepatic artery and/or portal vein) was carried out when R0 resection was expected.

\section{Statistical analysis}

Overall survival was measured from the day of operation to death, including the death caused by cancer or other factors, or to the last day of follow-up. All patients were followed up for more than 5 years unless the patients died within 5 years. The average follow-up time was 76.7 months. The comparison between the two groups was done by Student's $t$ test for parametric data and the Mann-Whitney $U$ test for non-parametric data. The Chi-square test was used for categorical data. Survival curves were estimated with the Kaplan-Meier method and compared by the log-rank test. Cox regression analysis was carried out to determine which factor was the best prognostic determinant. $P$ value $<0.05$ was considered statistically significant. Calculations were done by SPSS Version 17.0 for Windows (SPSS, Inc., Chicago, IL, USA).

\section{Results}

\section{Demographic data}

In this 10-year study, 536 patients with gallbladder carcinoma underwent surgery, of which 267 patients underwent radical resection ( $R 0$ resection, 49.8\%), 183 underwent $\mathrm{R} 1$ resection, and 86 underwent $\mathrm{R} 2$ resection. Among the $267 \mathrm{GBC}$ patients who underwent R0 resection, 105 were male and 162 were female, including 54 patients with preoperative jaundice. The average age was 58.6 years (range $23-83$ years).

\section{Preoperative management}

All 54 GBC patients with preoperative jaundice routinely underwent extrahepatic bile duct resection. The mean total bilirubin in 54 GBC patients with preoperative jaundice was $11.4 \mathrm{mg} / \mathrm{dl}$ (range $2.89-33.01 \mathrm{mg} / \mathrm{dl}$ ). Of the 54 patients, 34 patients $(61.1 \%)$ underwent preoperative biliary drainage according to liver function and the expected range of liver resection. Eighteen cases were treated with percutaneous transhepatic biliary puncture (PTBD), and 16 cases were treated with endoscopic biliary drainage (EBD). Among the 34 patients who underwent preoperative biliary drainage, the mean total bilirubin at admission was $15.6 \mathrm{mg} / \mathrm{dl}$ (range $7.79-33.01$ $\mathrm{mg} / \mathrm{dl}$ ), and decreased to $4.7 \mathrm{mg} / \mathrm{dl}$ (range $3.2-5.8 \mathrm{mg} / \mathrm{dl}$ ) before surgery. Four patients developed cholangitis, and two patients developed hemorrhage associated with preoperative biliary drainage, who were treated without sequela after conservative treatment. 
Table 1 Demographic data of jaundiced $(n=54)$ and non-jaundiced GBC patients $(n=213)$

\begin{tabular}{|c|c|c|c|}
\hline & Jaundiced, $n$ & Non-jaundiced, $n$ & $P$ value \\
\hline Male gender & 30 & 75 & 0.006 \\
\hline Mean age (range) & $58.04 \pm 10.87(35-80)$ & $59.21 \pm 10.60(23-83)$ & 0.478 \\
\hline Postoperative hospital stay & $18.31 \pm 12.91(4-85)$ & $10.92 \pm 5.66(5-51)$ & $<0.001$ \\
\hline Associated gallbladder disease & & & 0.285 \\
\hline Gallstones & $24(44.4 \%)$ & $116(54.5 \%)$ & \\
\hline Gallbladder polyp & $1(1.9 \%)$ & $2(0.9 \%)$ & \\
\hline $\mathrm{Nil}$ & $29(53.7 \%)$ & $95(44.6 \%)$ & \\
\hline Tumor location & & & $<0.001$ \\
\hline Gallbladder neck & $38(70.4)$ & 29 (13.6) & \\
\hline Gallbladder body + fundus & $16(29.6)$ & $184(86.4)$ & \\
\hline Histologic type & & & 0.107 \\
\hline Moderately + well-differentiated & $51(94.4)$ & $182(85.4)$ & \\
\hline Poorly differentiated & $3(5.6)$ & $31(14.6)$ & \\
\hline Extent of liver resection & & & $<0.001$ \\
\hline Major hepatectomy (> 3 segments) & $4(7.4 \%)$ & $1(0.6 \%)$ & \\
\hline Anatomical segments IV-V & $20(37.0 \%)$ & $146(68.5 \%)$ & \\
\hline Gallbladder bed & $30(55.6 \%)$ & $66(30.9 \%)$ & \\
\hline Extrahepatic bile duct resection & $54(100.0 \%)$ & $20(9.4 \%)$ & $<0.001$ \\
\hline Combined resection of adjacent organs & $9(16.7 \%)$ & $9(4.2 \%)$ & 0.003 \\
\hline Hepatic invasion & $29(53.7 \%)$ & $100(46.9 \%)$ & 0.446 \\
\hline Lymph node metastasis & $39(72.2 \%)$ & $94(44.1 \%)$ & $<0.001$ \\
\hline Vascular invasion & $5(9.3 \%)$ & $0(0 \%)$ & $<0.001$ \\
\hline pT & & & 0.004 \\
\hline pT2 & $0(0 \%)$ & $25(11.7 \%)$ & \\
\hline pT3 & 45 (83.3\%) & $174(81.7 \%)$ & \\
\hline pT4 & $9(16.7 \%)$ & $14(6.6 \%)$ & \\
\hline Intraoperative bleeding (ml) & $656.48 \pm 532.97(200-3200)$ & $329.67 \pm 257.13(200-1800)$ & $<0.001$ \\
\hline Operative time (min) & $296.02 \pm 76.91(100-470)$ & $211.88 \pm 80.10(100-400)$ & $<0.001$ \\
\hline Mortality (number of patients) & $2(3.7 \%)$ & $1(0.5 \%)$ & 0.105 \\
\hline Morbidity (need invasive treatment) & $15(27.8 \%)$ & $13(6.1 \%)$ & $<0.001$ \\
\hline
\end{tabular}

Note that adjacent organs include the pancreas, duodenum, stomach, and/or colon other than the liver and extrahepatic bile duct.

\section{Comparison between GBC patients with and without} preoperative jaundice who underwent $\mathrm{R} 0$ resection (Table 1)

There were no significant differences in age, associated gallbladder disease, histological differentiation, and hepatic invasion between patients with and without preoperative jaundice. Male patients were more common in the preoperative jaundice group. A more advanced pT stage was associated with preoperative jaundice, which suggested a more serious local tumor invasion. The extended hepatectomy was more common in the preoperative jaundice group. More intraoperative bleeding and operative time were found in the preoperative jaundice group $(P<0.001$ and $\mathrm{P}=0.001$ ), which suggested a wider range of lesion resection performed. As a result, the average postoperative hospital stay of GBC patients with preoperative jaundice was 18.3 days (range 4-85 days), which was longer than those without preoperative jaundice $(P<0.001)$.

In terms of tumor location, the most commonly occurring place was at the neck of the gallbladder in the preoperative jaundice group. There was no significant difference in the incidence of hepatic invasion between the two groups, although the incidence of lymphatic metastasis was significantly higher in the preoperative jaundice group. There was no significant difference in mortality between GBC patients with and without preoperative jaundice $(P=0.105)$. Morbidity was significantly higher in patients with preoperative jaundice than without preoperative jaundice (27.8\% vs. $6.1 \%, P<0.001)$. 
Table 2 Univariate analysis of 14 variables related to survival of GBC patients who underwent curative resection $(n=267)$

\begin{tabular}{|c|c|c|c|c|c|}
\hline \multirow[t]{2}{*}{ Variable } & \multirow[t]{2}{*}{ Cutoff level } & \multirow[t]{2}{*}{ Number } & \multicolumn{2}{|c|}{ Survival rates (\%) } & \multirow[t]{2}{*}{$P$ value } \\
\hline & & & 3 years & 5 years & \\
\hline \multirow[t]{3}{*}{ Age (years } & & & & & 0.019 \\
\hline & $<60$ & 133 & 42.2 & 32.0 & \\
\hline & $\geq 60$ & 134 & 28.2 & 15.3 & \\
\hline \multirow[t]{3}{*}{ Sex } & & & & & 0.158 \\
\hline & Male & 105 & 29.8 & 20.2 & \\
\hline & Female & 162 & 38.7 & 25.7 & \\
\hline \multirow[t]{3}{*}{ Jaundice } & & & & & $<0.001$ \\
\hline & Present & 54 & 13.0 & 1.9 & \\
\hline & Absent & 213 & 40.9 & 29.8 & \\
\hline \multicolumn{2}{|c|}{ Associated disease } & & & & 0.654 \\
\hline & Present & 143 & 36.0 & 25.2 & \\
\hline & Absent & 124 & 34.5 & 22.3 & \\
\hline \multicolumn{2}{|c|}{ Tumor location } & & & & 0.002 \\
\hline & Gallbladder neck & 67 & 20.3 & 9.4 & \\
\hline & Gallbladder body/fundus & 200 & 40.2 & 28.9 & \\
\hline \multirow[t]{3}{*}{ pT (TNM) } & & & & & $<0.001$ \\
\hline & pT1 and 2 & 25 & 83.8 & 78.6 & \\
\hline & pT3 and 4 & 242 & 30.2 & 18.0 & \\
\hline \multicolumn{2}{|c|}{ Lymph node metastasis } & & & & $<0.001$ \\
\hline & Negative & 134 & 52.2 & 38.9 & \\
\hline & Positive & 133 & 18.1 & 9.3 & \\
\hline \multicolumn{2}{|c|}{ Histologic differentiation } & & & & 0.049 \\
\hline & Well/moderate & 224 & 27.4 & 17.4 & \\
\hline & Poor & 43 & 36.7 & 24.9 & \\
\hline \multicolumn{2}{|c|}{ Hepatic invasion } & & & & $<0.001$ \\
\hline & Present & 129 & 20.6 & 11.1 & \\
\hline & Absent & 138 & 48.8 & 35.6 & \\
\hline \multirow[t]{3}{*}{ CRAO } & & & & & $<0.001$ \\
\hline & Present & 18 & 5.6 & 0.0 & \\
\hline & Absent & 249 & 36.9 & 25.0 & \\
\hline \multicolumn{3}{|c|}{ Combined portal vein/hepatic artery resection } & & & 0.027 \\
\hline & Present & 5 & 0.0 & 0.0 & \\
\hline & Absent & 262 & 35.8 & 24.1 & \\
\hline \multicolumn{2}{|c|}{ Intraoperative blood infusion } & & & & 0.006 \\
\hline & Present & 44 & 25.0 & 10.9 & \\
\hline & Absent & 223 & 37.1 & 26.5 & \\
\hline \multirow[t]{3}{*}{ Morbidity } & & & & & 0.004 \\
\hline & Conservative treatment & 239 & 37.6 & 25.1 & \\
\hline & Need invasive treatment & 28 & 14.3 & 5.4 & \\
\hline \multicolumn{2}{|c|}{ Extrahepatic bile duct resection } & & & & $<0.001$ \\
\hline & Present & 74 & 18.3 & 8.4 & \\
\hline & Absent & 193 & 41.7 & 30.0 & \\
\hline
\end{tabular}


Table 3 Results of multivariate analysis

\begin{tabular}{|c|c|c|c|c|c|}
\hline Variable & Regression coefficient & Standard error & $P$ value & Relative risk & $95 \% \mathrm{Cl}$ \\
\hline Age & 0.227 & 0.148 & 0.125 & 1.255 & $0.939-1.679$ \\
\hline Jaundice & 0.375 & 0.321 & 0.243 & 1.455 & $0.776-2.731$ \\
\hline Tumor location & -0.390 & 0.207 & 0.060 & 0.677 & $0.451-1.016$ \\
\hline pT & 0.796 & 0.360 & 0.027 & 2.217 & $1.095-4.491$ \\
\hline Lymph node metastasis & 0.537 & 0.158 & 0.001 & 1.711 & $1.255-2.331$ \\
\hline Hepatic invasion & 0.677 & 0.157 & 0.000 & 1.968 & $1.446-2.678$ \\
\hline CRAO & 0.160 & 0.296 & 0.588 & 1.174 & $0.657-2.096$ \\
\hline Combined PV/HA resection & 0.536 & 0.497 & 0.280 & 1.710 & $0.646-4.528$ \\
\hline Intraoperative blood infusion & -0.194 & 0.212 & 0.360 & 0.824 & $0.543-1.248$ \\
\hline $\begin{array}{l}\text { Extrahepatic bile } \\
\text { duct resection }\end{array}$ & -0.147 & 0.275 & 0.592 & 0.863 & $0.503-1.480$ \\
\hline Histologic differentiation & -0.360 & 0.200 & 0.071 & 0.697 & $0.472-1.031$ \\
\hline Morbidity (invasive treatment) & 0.078 & 0.253 & 0.759 & 1.081 & $0.658-1.775$ \\
\hline
\end{tabular}

Survival and risk factors in all 267 GBC patients who underwent $\mathrm{R} 0$ resection (Tables 2 and 3 )

The overall 3-year and 5-year survival rates of 267 patients were $35.2 \%$ and $23.7 \%$, respectively. The mean survival time was 36 months. According to the presence or absence of preoperative jaundice, the prognosis of 267 patients were analyzed. The 3-year survival rate and mean survival time were $40.9 \%$ and 40.8 months in 213 patients without preoperative jaundice, and $13.0 \%$ and 18.0 months in 54 patients with preoperative jaundice, respectively. The survival rate of patients with preoperative jaundice group was significantly worse than those in the group without jaundice $(P<0.001)$.

Univariate and multivariate analyses were given to determine the significant factors that affected long-term survival in 267 GBC patients who underwent R0 resection. In the univariate analysis, the significant prognostic factors include the depth of tumor invasion (pT stage), age, preoperative jaundice, tumor location, lymph node metastasis, hepatic invasion, combined resection of adjacent organs (CRAO), portal vein/hepatic artery (HA/PV) resection, intraoperative blood transfusion, extrahepatic bile duct resection, treatment of complications, and histologic differentiation (Table 2). In the multivariate analysis, only pT stage, lymph node metastasis, and hepatic invasion were independent factors (Table 3).

\section{Risk factors in $54 \mathrm{GBC}$ patients with preoperative jaundice who underwent $\mathrm{RO}$ resection (Table 4)}

Univariate and multivariate analysis were given to identify risk factors in $54 \mathrm{GBC}$ patients with preoperative jaundice who underwent $\mathrm{R} 0$ resection. In the univariate analysis, pT stage, tumor location, and histologic differentiation were identified as significant prognostic factors. In the multivariate analysis, only advanced pT stage was an independent risk factor for poor prognosis.

\section{Clinicopathologic features of seven 3-year survivors (Table 5)}

Of the $54 \mathrm{GBC}$ patients with preoperative jaundice, 7 survived for more than 3 years. They were 2 males and 5 females, with an average age of 57.4 years. Comparing the 7 jaundiced patients who survived for more than 3 years with those who did not, a significant difference of intraoperative blood transfusion and $\mathrm{pT}$ stage was observed.

\section{Discussion}

This was a large sample study and confirmed that jaundice was a predictor of advanced gallbladder cancer. The 3 -year survival rate and median survival time were $13.0 \%$ and 18.0 months for the 54 jaundiced patients, respectively, and $40.9 \%$ and 40.8 months for the 213 nonjaundiced ones, respectively $(P<0.001)$. The jaundiced patients had significantly lower survival rates than the non-jaundiced patients. In this study, the impact of preoperative jaundice on the prognosis of GBC patients after R0 resection was thoroughly evaluated. So far, no other report is known to be published. This study provided a basis and data support for clinical prognostic evaluation of GBC patients after R0 resection.

In previous reports, preoperative jaundice was an important predictor of advanced gallbladder carcinoma [11]. Although the surgical prognosis of advanced gallbladder cancer was not satisfactory, it was the only expected treatment to be cured $[6,8]$. Advanced gallbladder carcinoma was usually accompanied with adjacent organ invasion, such as the liver, transverse colon, duodenum, extrahepatic bile duct, hepatic artery, and portal vein. Enlarged surgical resection was required for radical resection. The morbidity and mortality of this operation were still high. It was reported that the postoperative complication rate was as high as 53\% and the 
Table 4 Univariate and multivariate analyses of 11 variables related to survival of GBC patients with preoperative jaundice $(n=54)$

\begin{tabular}{|c|c|c|c|c|c|c|c|}
\hline \multirow[t]{2}{*}{ Variable } & \multirow[t]{2}{*}{ Cutoff level } & \multirow[t]{2}{*}{ Number } & \multicolumn{2}{|c|}{ Survival rates (\%) } & \multirow{2}{*}{$\begin{array}{l}\text { Univariate } \\
P \text { value }\end{array}$} & \multicolumn{2}{|l|}{ Multivariate } \\
\hline & & & 1 year & 3 years & & RR $(95 \% \mathrm{Cl})$ & $P$ \\
\hline \multirow[t]{3}{*}{ Age (year) } & & & & & 0.334 & & \\
\hline & $<60$ & 26 & 50.0 & 11.5 & & & \\
\hline & $\geq 60$ & 28 & 25.5 & 15.3 & & & \\
\hline \multirow[t]{3}{*}{ Sex } & & & & & 0.391 & & \\
\hline & Male & 30 & 53.3 & 6.7 & & & \\
\hline & Female & 24 & 54.2 & 20.8 & & & \\
\hline \multicolumn{2}{|c|}{ Preoperative Biliary Drainage } & & & & 0.151 & & \\
\hline & Present & 34 & 51.5 & 6.1 & & & \\
\hline & Absent & 20 & 57.1 & 23.8 & & & \\
\hline \multicolumn{2}{|c|}{ Associated disease } & & & & 0.672 & & \\
\hline & Present & 25 & 44.0 & 16.0 & & & \\
\hline & Absent & 29 & 62.1 & 10.3 & & & \\
\hline \multicolumn{2}{|c|}{ Tumor location } & & & & 0.050 & $1.288(0.626-2.650)$ & 0.492 \\
\hline & Gallbladder neck & 38 & 63.2 & 15.8 & & & \\
\hline & Gallbladder body/fundus & 16 & 31.3 & 6.3 & & & \\
\hline \multirow[t]{3}{*}{$\mathrm{pT}(\mathrm{TNM})$} & & & & & 0.010 & $2.221(1.065-4.631)$ & 0.033 \\
\hline & pT3 & 14 & 64.3 & 35.7 & & & \\
\hline & pT4 & 40 & 50.0 & 5.0 & & & \\
\hline \multicolumn{2}{|c|}{ Lymph node metastasis } & & & & 0.136 & & \\
\hline & Negative & 15 & 66.7 & 13.3 & & & \\
\hline & Positive & 39 & 48.7 & 12.8 & & & \\
\hline \multicolumn{2}{|c|}{ Histologic differentiation } & & & & 0.025 & $0.521(0.216-1.253)$ & 0.145 \\
\hline & Well/moderate & 47 & 59.6 & 14.9 & & & \\
\hline & Poor & 7 & 14.3 & 0.0 & & & \\
\hline \multirow[t]{3}{*}{ CRAO } & & & & & 0.545 & & \\
\hline & Present & 9 & 44.4 & 11.1 & & & \\
\hline & Absent & 45 & 55.6 & 13.3 & & & \\
\hline \multicolumn{2}{|c|}{ Intraoperative blood infusion } & & & & 0.137 & & \\
\hline & Present & 23 & 56.5 & 26.1 & & & \\
\hline & Absent & 31 & 51.6 & 3.2 & & & \\
\hline \multirow[t]{3}{*}{ Morbidity } & & & & & 0.301 & & \\
\hline & Present & 15 & 53.3 & 6.7 & & & \\
\hline & Absent & 39 & 53.8 & 15.4 & & & \\
\hline
\end{tabular}

mortality was $4-27 \%$ in extended hepatectomy [14]. With the advent of preoperative biliary drainage and portal vein embolization (PVE), extended hemihepatectomy, mainly extended right hepatectomy, was safer and more feasible. Although extended hemihepatectomy was expected to remove tumor lesions radically, the postoperative mortality was higher and survival benefits remained controversial [15]. In addition, the local radical resection with more liver parenchyma reservation was expected to achieve similar prognosis [16]. In short, the advantages and disadvantages of extended surgery should be carefully weighed. This study has found that the jaundiced group had a worse prognosis than the non-jaundiced group, suggesting that preoperative jaundice was identified as advanced stage. However, there was no specific correlation between preoperative jaundice and long-term survival.

In previous reports, hilar invasion was identified as an important prognostic factor [10,17]. The clinical manifestation of hilar invasion was jaundice, which was an independent factor for poor prognosis [10, 17]. In our previous study, the lymph node metastasis and 
Table 5 Compared analyses for jaundiced patients with and without long survival $(n=54)$

\begin{tabular}{|c|c|c|c|}
\hline Variables & Survived more than 3 years, $n=7$ & $\begin{array}{l}\text { Died within } 3 \text { years, } \\
n=47\end{array}$ & $P$ value \\
\hline Male gender & 2 & 28 & 0.221 \\
\hline Mean age & $57.43 \pm 10.96$ & $62.14 \pm 10.06$ & 0.288 \\
\hline Associated gallbladder stone & 4 & 21 & 0.692 \\
\hline Preoperative biliary drainage & 2 & 31 & 0.096 \\
\hline Tumor location & & & 0.660 \\
\hline Neck & $6(85.7 \%)$ & $32(68.1 \%)$ & \\
\hline Body/fundus & $1(14.3 \%)$ & $15(31.9 \%)$ & \\
\hline Postoperative hospital stay & $12.29 \pm 3.82$ & $19.21 \pm 13.56$ & 0.188 \\
\hline Bilirubin level at presentation & $183.06 \pm 103.79$ & $251.93 \pm 133.50$ & 0.149 \\
\hline Intraoperative bleeding (ml) & $785.71 \pm 371.61$ & $637.23 \pm 553.49$ & 0.380 \\
\hline Intraoperative blood infusion & $6(85.7 \%)$ & $17(36.2 \%)$ & 0.034 \\
\hline Operative time (min) & $320.00 \pm 80.83$ & $292.45 \pm 76.57$ & 0.423 \\
\hline Combined resection of adjacent organs & $1(14.3 \%)$ & $8(17 \%)$ & 0.670 \\
\hline Hepatic invasion & $4(57.1 \%)$ & $25(53.2 \%)$ & 0.585 \\
\hline $\mathrm{pT}(\mathrm{TNM})$ & & & 0.010 \\
\hline pT3 & $5(71.4 \%)$ & $9(19.1 \%)$ & \\
\hline pT4 & $2(28.6 \%)$ & $38(80.9 \%)$ & \\
\hline Lymph node metastasis & $5(71.4 \%)$ & $34(72.3 \%)$ & 0.637 \\
\hline Histologic type & & & 0.576 \\
\hline Well + moderately differentiated & $7(100 \%)$ & $40(85.1 \%)$ & \\
\hline Poorly differentiated & $0(0 \%)$ & $7(14.9 \%)$ & \\
\hline Extent of liver resection & & & 0.219 \\
\hline Major hepatectomy (> 3 segments) & $0(0 \%)$ & $4(8.5 \%)$ & \\
\hline Anatomical segments IV-V & $1(14.3 \%)$ & $19(40.4 \%)$ & \\
\hline Gallbladder bed & $6(85.7 \%)$ & $24(51.1 \%)$ & \\
\hline CRAO & & & 0.670 \\
\hline Yes & $1(14.3 \%)$ & $8(17.0 \%)$ & \\
\hline No & $6(85.7 \%)$ & $3(83.0 \%)$ & \\
\hline Combined portal vein/hepatic artery resection & $0(0 \%)$ & $5(10.6 \%)$ & 0.485 \\
\hline Incidence of incidental gallbladder cancer (IGC) & $1(14.3 \%)$ & 1 (2.13\%_) & 0.2445 \\
\hline
\end{tabular}

gallbladder neck tumors were the only significant risk factors of poor prognosis in GBC patients who underwent surgical resection with curative intent (R0 and R1 resections) [12]. However, in this study, preoperative jaundice and gallbladder neck tumors were not the independent factors associated with poor prognosis after R0 resection, which suggested that GBC patients with preoperative jaundice and gallbladder neck tumors should be actively given surgery, if R0 resection was expected. This was different from previous research results. This again emphasized the clinical importance of radical resection.

In addition, another important predictor of poor prognosis in gallbladder cancer was lymph node metastasis [17-19]. Kondo et al. [20] insisted that surgery cannot improve the prognosis of gallbladder cancer patients with lymph node metastasis around the abdominal aorta. In contrast, reports from the Japanese Society of Biliary Surgery have found that GBC patients with extensive lymph node metastasis also benefit from lymphadenectomy $[10,19]$. The univariate analysis of this study has found that lymph node metastasis was closely associated with survival $(P<0.001)$. However, the multivariate analysis of this study has found that regional lymph node involvement was not an independent prognostic factor for long-term survival, and only $\mathrm{pT}$ stage was a key prognostic factor. With the continuous advancement of imaging technologies such as CT, MRI, and PET-CT [21], the pT stage can be more accurately evaluated before surgery. Therefore, once more advanced $\mathrm{pT}$ stage 
(pT4) was suggested by preoperative imaging, the choice of surgical indications and multidisciplinary treatment should be more cautious.

The limitation of this study is the limited amount of cases. Further multicenter studies are needed to confirm this conclusion. In addition, there are limitations in retrospective research itself. In conclusion, this study suggested that there was no absolute relation between preoperative jaundice and poor long-term prognosis. The $\mathrm{pT}$ staging was a key long-term prognostic factor for gallbladder carcinoma after R0 resection.

\section{Abbreviation}

GBC: Gallbladder cancer; RO: Radical resection; PT: Depth of tumor invasion; PVE: Portal vein embolization; PTBD: Percutaneous transhepatic biliary puncture; EBD: Endoscopic biliary drainage; CRAO: Combined resection of adjacent organs; PV: Portal vein; HA: Hepatic artery; OS: Overall survival; DFS: Disease-free survival

\section{Acknowledgements}

We are grateful to Du Jing, Zhang Guan-xia, and Zhang Bai-he for their assistance in the preparation of this manuscript.

\section{Authors' contributions}

XWY, ZJW, FYW, and JYC performed the majority of the research and collected all the clinicopathological data. XWY wrote the manuscript. JY, YJC, and $\mathrm{LL}$ provided analytical tools and edited the manuscript. $\mathrm{BHZ}$ and SF designed the study. XWY, ZJW, JYC, YLL, and FYW equally contributed to the present study. The authors read and approved the final manuscript. ZJW, YLL and JYC are the co-first authors.

\section{Funding}

This research was funded by grants from the National Natural Science Foundation of China (No. 81902940), Shanghai Municipal Health and Family Planning Commission ( No. 20164Y0109), National Key R\&D Program ( No. 2016YFC1101402), and Health Planning Commission of Hongkou District in Shanghai ( No. 1802-05)

\section{Availability of data and materials}

The datasets used and analyzed during the current study are available from the corresponding author on reasonable request.

\section{Ethics approval and consent to participate}

All studies were approved by the Committee on Ethics of Second Military Medical University. Permission from Second Military Medical University's Institutional Review Board was obtained prior to data review.

\section{Consent for publication}

Written informed consent was obtained from all patients for surgical treatment, pathological examinations, and further analysis according to the institutional guidelines.

\section{Competing interests}

The authors declare that they have no competing interests.

\section{Author details}

'Eastern Hepatobiliary Surgery Hospital, Second Military Medical University, Changhai Road 225, Shanghai 200438, China. ${ }^{2}$ Department of General Surgery, The Fourth People's Hospital of Shanghai, North Sichuang Road 1878, Shanghai 200081, Shanghai, China. ${ }^{3}$ Department of General Surgery, No.73 Army Hospital of PLA, Xiamen University, Xiamen, China. ${ }^{4}$ Department of General Surgery, Jiangdu People's Hospital of Yangzhou City, Jiangsu Province, No. 9 Dongfanghong East Road, Yangzhou, China.
Received: 28 February 2020 Accepted: 26 August 2020

Published online: 05 September 2020

\section{References}

1. Shukla SK, Singh G, Shahi KS, Bhuvan PP. Staging, treatment, and future approaches of gallbladder carcinoma. J Gastrointest Cancer. 2018;49:9-15.

2. Hawkins WG, DeMatteo RP, Jarnagin WR, Ben-Porat $L$, Blumgart LH, Fong $Y$. Jaundice predicts advanced disease and early mortality in patients with gallbladder cancer. Ann Surg Oncol. 2004;11:310-5.

3. Misra S, Chaturvedi A, Misra NC, Sharma ID. Carcinoma of the gallbladder. Lancet Oncol. 2003:4:167-76.

4. D'Angelica M, Dalal KM, DeMatteo RP, Fong $Y$, Blumgart LH, Jarnagin WR. Analysis of the extent of resection for adenocarcinoma of the gallbladder. Ann Surg Oncol. 2009;16:806-16.

5. Dixon E, Vollmer CM Jr, Sahajpal A, Cattral M, Grant D, Doig C, et al. An aggressive surgical approach leads to improved survival in patients with gallbladder cancer: a 12-year study at a North American Center. Ann Surg. 2005;241:385-94.

6. Shimada K, Nara S, Esaki M, Sakamoto Y, Kosuge T, Hiraoka N. Extended right hemihepatectomy for gallbladder carcinoma involving the hepatic hilum. Br J Surg. 2011;98:117-23.

7. Pilgrim C, Usatoff $V$, Evans PM. A review of the surgical strategies for the management of gallbladder carcinoma based on T stage and growth type of the tumour. Eur J Surg Oncol. 2009;35:903-7.

8. Fong $Y$, Jarnagin W, Blumgart LH. Gallbladder cancer: comparison of patients presenting initially for definitive operation with those presenting after prior noncurative intervention. Ann Surg. 2000;232:557-69.

9. Shih SP, Schulick RD, Cameron JL, Lillemoe KD, Pitt HA, Choti MA, et al. Gallbladder cancer: the role of laparoscopy and radical resection. Ann Surg. 2007;245:893-901.

10. Nishio H, Ebata T, Yokoyama Y, Igami T, Sugawara G, Nagino M. Gallbladder cancer involving the extrahepatic bile duct is worthy of resection. Ann Surg. 2011;253:953-60.

11. Regimbeau JM, Fuks D, Bachellier P, Le Treut YP, Pruvot FR, Navarro F, et al. Prognostic value of jaundice in patients with gallbladder cancer by the AFC- GBC-2009 study group. Eur J Surg Oncol. 2011;37:505-12.

12. Yang XW, Yuan JM, Chen JY, Yang J, Gao QG, Yan XZ, et al. The prognostic importance of jaundice in surgical resection with curative intent for gallbladder cancer. BMC Cancer. 2014;14:652.

13. AJCC. Cancer staging manual. 8th ed. New York: Springer; 2016.

14. Araida T, Yoshikawa T, Azuma T, Ota T, Takasaki K, Hanyu F. Indications for pancreatoduodenectomy in patients undergoing lymphadenectomy for advanced gallbladder carcinoma. J Hepatobiliary Pancreat Surg. 2004;1 1:45-9.

15. Kondo S, Nimura Y, Kamiya J, Nagino M, Kanai M, Uesaka K, et al. Factors influencing postoperative hospital mortality and long-term survival after radical resection for stage IV gallbladder carcinoma. World J Surg. 2003;27: 272-7.

16. Agarwal AK, Mandal S, Singh S, Bhojwani R, Sakhuja P, Uppal R. Biliary obstruction in gallbladder cancer is not sine qua non of inoperability. Ann Surg Oncol. 2007;14:2831-7.

17. Higuchi R, Ota T, Araida T, Kajiyama H, Yazawa T, Furukawa T, et al. Surgical approaches to advanced gallbladder cancer: a 40-year single-institution study of prognostic factors and resectability. Ann Surg Oncol. 2014;21:4308-16.

18. Jensen EH, Abraham A, Jarosek S, Habermann EB, Al-Refaie WB, Vickers SA, et al. Lymph node evaluation is associated with improved survival after surgery for early stage gallbladder cancer. Surgery. 2009;146:706-11 discussion 711-3.

19. Kondo S, Takada T, Miyazaki M, Miyakawa S, Tsukada K, Nagino M, et al. Guidelines for the management of biliary tract and ampullary carcinomas: surgical treatment. J Hepatobiliary Pancreat Surg. 2008;15:41-54.

20. Kondo S, Nimura Y, Hayakawa N, Kamiya J, Nagino M, Uesaka K. Regional and para-aortic lymphadenectomy in radical surgery for advanced gallbladder carcinoma. Br J Surg. 2000;87:418-22.

21. Rodríguez-Fernández A, Gómez-Río M, Medina-Benítez A, Moral JV, RamosFont C, Ramia-Angel JM, et al. Application of modern imaging methods in diagnosis of gallbladder cancer. J Surg Oncol. 2006;93:650-64.

\section{Publisher's Note}

Springer Nature remains neutral with regard to jurisdictional claims in published maps and institutional affiliations. 